\title{
BMJ Open Structural brain lesions and restless legs syndrome: a cross-sectional population-based study
}

\author{
Pamela M Rist, ${ }^{1,2}$ Christophe Tzourio, ${ }^{3,4}$ Alexis Elbaz, ${ }^{5,6}$ Aïcha Soumaré, ${ }^{3}$ \\ Carole Dufouil, ${ }^{3,4}$ Bernard Mazoyer, ${ }^{4,7}$ Tobias Kurth ${ }^{1,2,3,4}$
}

To cite: Rist PM, Tzourio C, Elbaz A, et al. Structural brain lesions and restless legs syndrome: a crosssectional population-based study. BMJ Open 2014;4: e005938. doi:10.1136/ bmjopen-2014-005938

- Prepublication history for this paper is available online. To view these files please visit the journal online (http://dx.doi.org/10.1136/ bmjopen-2014-005938).

Received 18 June 2014 Revised 23 July 2014 Accepted 24 July 2014
CrossMark

For numbered affiliations see end of article.

Correspondence to Dr Pamela M Rist; prist@mail.harvard.edu

\section{ABSTRACT}

Objective: To evaluate the association between white matter lesion (WML) volume, silent infarcts and restless legs syndrome (RLS) in a population-based study of elderly individuals.

Design: Cross-sectional study.

Setting: Population-based Three-City study. Participants: 1035 individuals from the Dijon, France, centre of the Three-City study who had available information on volume of WMLs from MRIs and who answered questions about the prevalence of RLS.

Primary outcome measure: Prevalence of RLS.

Results: WML volume was measured using an automated tissue segmentation method. Logistic regression was used to evaluate adjusted associations between tertiles of WML volume and RLS and between silent infarcts and RLS. 218 individuals (21.1\%) were determined to have RLS. Compared with those in the first tertile of WML volume, individuals in the second tertile $(\mathrm{OR}=1.09 ; 95 \% \mathrm{Cl} 0.75$ to 1.60$)$ or third tertile $(\mathrm{OR}=1.17 ; 95 \% \mathrm{Cl} 0.79$ to 1.74$)$ did not have an increased prevalence of RLS. We also did not observe associations between the volume of deep or periventricular WML and RLS; nor did we observe an association between silent brain infarcts and RLS (OR=0.74; $95 \% \mathrm{Cl} 0.40$ to 1.39). These findings were not modified by age or gender.

Conclusions: Higher volume of WML and the presence of silent infarcts were not associated with an increased prevalence of RLS in this population-based cohort of elderly individuals.

\section{INTRODUCTION}

Restless legs syndrome (RLS) is a neurological disorder that originates in the motoneurons of the brain and is characterised by an urge to move the legs and unpleasant leg sensations. Population-based studies using the minimal diagnostic criteria from the International Restless Legs Syndrome Study Group $^{12}$ have found the prevalence of RLS ranges from $6 \%$ to $12 \%$ with women being affected twice as often as men. ${ }^{3}$ In addition, the prevalence of RLS increases with age. ${ }^{3}$

\section{Strengths and limitations of this study}

- Strengths include the population-based setting with available brain imaging and the size of the cohort.

- Additionally, we performed a standardised assessment of restless legs syndrome using criteria from the International Restless Legs Study Group and used an automated measurement procedure to quantify and localise white matter lesions.

- Limitations to this study include its crosssectional design, lack of information on kidney disease or iron deficiency for participants, and self-reported information on RLS.

While the causes of RLS are unknown, some studies have suggested that dysfunction of the dopaminergic system may contribute to disease development. However, neuroimaging studies have not shown any primary neurodegeneration of dopaminergic neurons in the substantia nigra. ${ }^{4}$ A large genetics consortium study has found some genetic variants that may be associated with the development of RLS. ${ }^{5}$

Several studies have found associations between cardiovascular risk factors including smoking, ${ }^{6-10}$ diabetes, ${ }^{7}{ }^{11}$ hypercholerolaemia, ${ }^{9}{ }^{10}$ exercise, ${ }^{9}$ body mass index ${ }^{6} \quad \begin{array}{lll}9 & 12\end{array}$ and hypertension ${ }^{71} 15$ and RLS. These associations have led to the hypothesis that RLS may be a risk factor for cardiovascular disease. However, evidence for an association between RLS and incident cardiovascular disease is mixed. ${ }^{6911}{ }^{15-20}$ One recent longitudinal study did not find evidence of an association between RLS and incident cardiovascular disease ${ }^{21}$ while others found an association between RLS and coronary heart disease $^{22}$ and mortality. ${ }^{23}$ Several possible biological mechanisms have been proposed to explain why RLS may be associated with high blood pressure, heart disease and 
stroke. RLS is associated with sympathetic hyperactivity which may lead to daytime hypertension which itself is a risk factor for heart disease and stroke. Alternatively, even if the sympathetic hyperactivity does not lead to daytime hypertension, it may impact atherosclerotic plaque formation and rupture which could lead to heart disease and stroke. Other comorbidities associated with RLS may also be risk factors for heart disease and stroke. ${ }^{24}$ In addition to its association with cardiovascular risk factors, RLS is also associated with migraine in men and women. ${ }^{25} 26$

Given the association of RLS with several vascular risk factors as well as with migraine, we were interested to know if white matter lesions (WMLs), which are also strongly related to vascular risk factors, including migraine, and cardiovascular disease, were associated with RLS. Using a population-based cohort of elderly individuals residing in France, we examined the crosssectional association between WML volume and RLS prevalence.

\section{METHODS}

The Three-City (3C) is a longitudinal cohort study enrolling participants living in three French cities (Bordeaux, Dijon and Montpellier) designed to estimate the risk of dementia and cognitive impairment attributable to vascular risk factors. ${ }^{27}$ The present analysis only uses data from participants living in Dijon because data on RLS were only collected in that city. Each participant signed an informed consent statement.

To be eligible for the 3C study, the participant needed to live in Dijon, be registered on the electoral rolls in 1999, be 65 years or older and not be institutionalised. A total of 4931 individuals were recruited at the Dijon site between 1999 and 2001. For the MRI substudy, all participants recruited from the Dijon centre who were $<80$ years of age and enrolled between June 1999 and September 2000 were eligible to participate. Of those eligible, $2285(82 \%)$ participants agreed to participate in the MRI study, but only 1924 scans could be performed at baseline due to financial constraints.

The process of obtaining the MRI information has been described in detail elsewhere. ${ }^{28}{ }^{29}$ In brief, MRIs were obtained using a $1.5 \mathrm{~T}$ Magnetom (Siemens, Erlangen, Germany). A three-dimensional (3D) highresolution T1-weighted brain volume was obtained using a 3D inversion recovery fast spoiled-gradient echo sequence. T2-weighted and proton density (PD)-weighted brain volumes were acquired using a 2-D dual spin echo sequence with two echo times. Each participant data set (T1, T2, PD) was reconstructed and visually checked for major artefacts before being stored.

A fully automated image processing software was used to detect, measure and localise WMLs. The process has been described in detail previously. ${ }^{28}{ }^{29}$ Based on the morphological parameters (centre of mass coordinates, Euclidian distance to the ventricular system, principal axes dimension), each WML was labelled as being either periventricular if the distance to the ventricular system was $<10 \mathrm{~mm}$ or deep otherwise. Total volume of periventricular and deep WMLs were estimated by summing the volumes of all periventricular and deep lesions.

We $\log$ transformed the values of total WML, periventricular WML, deep WML and total white matter volume as they were not normally distributed. We then divided the log-transformed values into tertiles to allow for nonlinear associations between WML volumes and RLS.

Infarcts were rated on T1-weighted, T2-weighted and PD-weighted images and defined as focal lesions $\geq 3 \mathrm{~mm}$ in diameter with the same signal characteristic as cerebrospinal fluid on all sequences. They were discriminated from dilated Virchow-Robin spaces using multiplanar reformatting. Those with a typical vascular shape and following the orientation of perforating vessels were classified as dilated Virchow-Robin spaces and not as infarcts. ${ }^{30}$

\section{RLS assessment}

RLS was assessed at the fifth and sixth follow-up waves of the study. Participants were asked series of questions designed to address the four minimal diagnostic criteria of the International Restless Legs Study Group which has been established and validated in previous studies. ${ }^{31}{ }^{32}$ The participants were asked: "Have you ever felt unpleasant sensation in the legs (restlessness, tingling, tension, annoyance, annoyances, contractions, twitching, numbness, electricity, etc) with the irresistible need or want to move?" Response options were yes or no. If the participant responded 'yes', he or she was further asked: "Do these unpleasant sensations occur solely or mainly at rest (when you are sitting or lying down, without moving your legs) and do they improve with movement?" and "Are these unpleasant sensations more intense in the evening or at night than in the morning?" Response options for these questions were yes or no. If the participant responded yes to all three questions, he or she was defined as having RLS.

\section{Covariates}

Trained psychologists collected sociodemographic and medical data on participants during home visits. Participants were asked if they were treated for various comorbidities at baseline and in the fifth and sixth waves of the study. We used all available information from baseline to RLS assessment to determine a participant's comorbidity history. History of cardiovascular disease was defined as a history of myocardial infarction, stroke, angina, percutaneous transluminal coronary angioplasty or coronary artery bypass surgery. History of diabetes was defined as glycaemia $\geq 7 \mathrm{mmol} / \mathrm{L}$ or use of antidiabetic treatment. ${ }^{33}$ High blood pressure was defined as measured systolic blood pressure $\geq 140 \mathrm{~mm} \mathrm{Hg}$ or measured diastolic blood pressure $\geq 90 \mathrm{~mm} \mathrm{Hg}$. High cholesterol was defined as lipid lowering treatment or cholesterol $\geq 6.2 \mathrm{mmol} / \mathrm{L}$. Information was also collected on history 
of peripheral artery disease, history of leg operation and history of oedema/swelling of legs and ankles.

For the following covariates, we used values from the follow-up waves during which RLS was assessed: body mass index, smoking status, alcohol consumption and physical activity. If this value was missing, we used values from baseline. Height and weight were used to calculate body mass index. Smoking status was reported as never, past or current, and alcohol consumption was measured in grams per day. Owing to changes in the questionnaires on physical activity over time, we classified participants as active versus non-active.

\section{Statistical analysis}

Of the 1924 individuals in the MRI substudy, 1189 were still alive and participating in the 3C study during the waves in which RLS was assessed. We excluded 97 participants who did not answer any of the questions about RLS and the 57 participants who did not have data on total WML volume, leaving a total of 1035 participants eligible for our analyses of which 218 (21.1\%) reported RLS (figure 1).

We performed a cross-sectional analysis using logistic regression to calculate ORs and 95\% CIs of reporting RLS for each tertile of WML volume using the lowest tertile as the reference group. Analyses examining the association between tertiles of total WML volume and RLS adjusted for tertiles of total white matter as the likelihood of WML correlate with the size of the total white matter. Analyses examining the association between tertiles of periventricular or deep WML and RLS adjusted for tertiles of WML. We also used logistic regression to examine the association between any silent brain infarct and RLS. For the infarct analyses, we excluded participants with a brain tumour detected at MRI.

We performed age-adjusted and sex-adjusted analyses and multivariable-adjusted analyses. Our multivariable

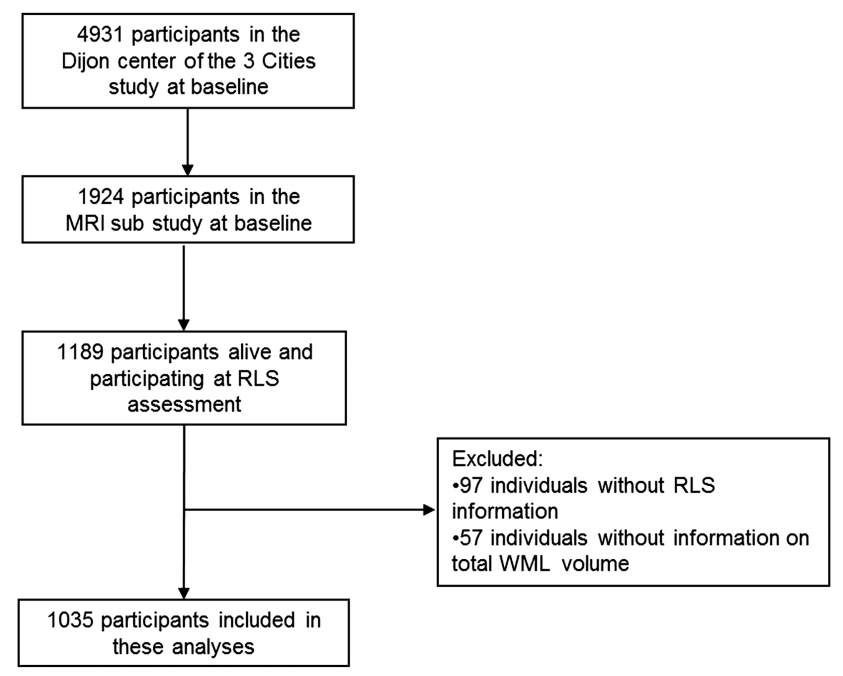

Figure 1 Flow chart of participants included in this analysis (RLS, restless legs syndrome; WML, white matter lesions). analyses adjusted for age (continuous), sex, smoking status (never, past or current smoker), alcohol consumption $(0,0$ to $\leq 12,12$ to $\leq 24$ and $>24 \mathrm{~g} /$ day $)$, physical activity (active vs not active), body mass index $(<25,25$ to $<30$ and $\geq 30 \mathrm{~kg} / \mathrm{m}^{2}$ ), history of hypertension (yes/ no), history of diabetes (yes/no), history of cardiovascular disease (yes/no), history of peripheral artery disease (yes/no), history of leg operation (yes/no) and history of oedema/swelling of legs and ankles (yes/no). Further adjustment for measures of sleep quality, difficulty sleeping and taking sleep medications did not affect our results (results not shown). All covariates were measured at baseline. Less than 39 people were missing information on any covariate, except for quality of sleep and were assigned to the reference value of that covariate. We created a separate category for those missing information on quality of sleep. We also performed separate age-adjusted analyses stratified by sex or mean age (72 years).

We considered a two-tailed $p$ value of $<0.05$ as statistically significant and used SAS V.9.3 as statistical software (Cary, North Carolina, USA).

\section{RESULTS}

The characteristics of the participants by RLS status can be seen in table 1 . Those who reported RLS were more likely to be women, never-smokers, non-drinkers, and were less physically active than those who did not report RLS.

We did not observe an association between tertiles of WML and RLS (table 2). Compared with those in the lowest tertile of WML, the multivariable-adjusted OR of reporting RLS was 1.09 (95\% CI 0.75 to 1.60 ) for those in the second tertile and 1.17 (95\% CI 0.79 to 1.74) for those in the top tertile. We also did not observe an association between tertiles of deep or periventricular WML and RLS (table 2).

We also performed age-adjusted analyses stratified by sex or mean age (72 years). Among men, compared with those in the lowest tertile of WML, the age-adjusted OR of reporting RLS was 0.74 (95\% CI 0.35 to 1.56 ) for those in the second tertile and 0.85 (95\% CI 0.41 to 1.77) for those in the top tertile. Among women, compared with those in the lowest tertile of WML, the age-adjusted OR of reporting RLS was 1.17 (95\% CI 0.76 to 1.81) for those in the second tertile and 1.13 (95\% CI 0.72 to 1.78 ) for those in the top tertile. For those under 72 years of age, the age-adjusted OR of reporting RLS was 0.99 (95\% CI 0.61 to 1.62) for those in the second tertile and 1.03 (95\% CI 0.61 to 1.75 ) for those in the top tertile compared with those in the lowest tertile of WML. For those 72 years of age or older, the age-adjusted OR of reporting RLS was 1.10 (95\% CI 0.61 to 1.98 ) for those in the second tertile and 1.20 (95\% CI 0.68 to 2.10) for those in the top tertile compared with those in the lowest tertile of WML.

We also explored whether there was an association between infarcts and RLS. Of the 1031 people with 
Table 1 Characteristics of participants by RLS status

\begin{tabular}{|c|c|c|}
\hline Characteristic (\%)* & $\begin{array}{l}\text { No RLS } \\
(n=817)\end{array}$ & $\begin{array}{l}\text { RLS } \\
(n=218)\end{array}$ \\
\hline Age (mean, SD) & $71.6(3.9)$ & $71.6(3.8)$ \\
\hline Sex (\% female) & 59.7 & 72.9 \\
\hline \multicolumn{3}{|l|}{ Smoking status (\%) } \\
\hline Never & 61.3 & 67.0 \\
\hline Past & 33.5 & 26.6 \\
\hline Current & 5.1 & 6.4 \\
\hline \multicolumn{3}{|l|}{ Alcohol consumption (\%) } \\
\hline Non-drinker & 18.1 & 22.0 \\
\hline 0 to $\leq 12 \mathrm{~g} /$ day & 44.6 & 21.4 \\
\hline 12 to $\leq 24 \mathrm{~g} /$ day & 19.2 & 19.3 \\
\hline$>24$ g/day & 15.3 & 11.5 \\
\hline Physically active (\%) & 55.9 & 63.8 \\
\hline \multicolumn{3}{|l|}{ Body mass index $\left(\mathrm{kg} / \mathrm{m}^{2}\right)$} \\
\hline$<25$ & 51.4 & 56.0 \\
\hline 25 to $<30$ & 38.8 & 32.6 \\
\hline$\geq 30$ & 9.8 & 11.5 \\
\hline $\begin{array}{l}\text { History of high blood } \\
\text { pressure }(\%)\end{array}$ & 73.3 & 71.6 \\
\hline History of high cholesterol (\%) & 58.0 & 51.4 \\
\hline History of diabetes (\%) & 13.0 & 9.2 \\
\hline $\begin{array}{l}\text { History of cardiovascular } \\
\text { disease }(\%)\end{array}$ & 11.3 & 7.8 \\
\hline History of stroke (\%) & 4.5 & 1.4 \\
\hline $\begin{array}{l}\text { History of peripheral artery } \\
\text { disease (\%) }\end{array}$ & 2.1 & 2.8 \\
\hline History of leg operation (\%) & 0.6 & 0.5 \\
\hline $\begin{array}{l}\text { History of oedema/swelling } \\
\text { of legs and ankles (\%) }\end{array}$ & 19.1 & 25.2 \\
\hline \multicolumn{3}{|l|}{ Difficulty sleeping } \\
\hline Never & 19.6 & 14.2 \\
\hline Rarely & 52.6 & 46.8 \\
\hline Regularly & 13.1 & 19.3 \\
\hline Often & 12.5 & 16.5 \\
\hline \multicolumn{3}{|l|}{ Quality of sleep } \\
\hline Good & 46.9 & 31.2 \\
\hline Average & 30.4 & 38.5 \\
\hline Mediocre or bad & 9.4 & 13.8 \\
\hline Take medications for sleep & 31.2 & 36.7 \\
\hline $\begin{array}{l}\text { Volume of white matter } \\
\text { hyperintensities }\left(\mathrm{cm}^{3},\right. \\
\text { median and IQR) }\end{array}$ & $3.9(2.7-5.8)$ & $4.0(2.7-6.0)$ \\
\hline
\end{tabular}

information on brain infarcts, 88 had a brain infarct and 218 reported RLS. The age-adjusted and sex-adjusted OR between infarcts and RLS was 0.68 (95\% CI 0.37 to 1.27). The multivariable-adjusted $\mathrm{OR}$ between infarcts and RLS was 0.78 (95\% CI 0.42 to 1.46 ).

\section{DISCUSSION}

In this large, population-based study of elderly individuals, we found no cross-sectional association between WML volume or brain infarcts and RLS. The results of this study do not support an association between RLS and vascular brain lesions.
Previous research on the association between WML volume and RLS is limited. A small study of 45 patients found that white matter hyperintensities were correlated with total limb movements per hour of sleep after adjusting for hypertension $(\mathrm{r}=0.66, \mathrm{p}=0.01){ }^{34}$ The authors suggest that leg movements may be associated with poor quality sleep which may contribute to episodes of nocturnal hypertension. Although nocturnal hypertension has been associated with the development of white matter hyperintensities even among those with daytime hypertension, ${ }^{35}$ this study did not present results on the association between RLS and white matter hyperintensities. Additionally, it is unclear if the authors adjusted for other potential confounders including age and sex.

Another study using data from the Memory and Morbidity in Augsburg Elderly Study (MEMO) examined the association between RLS and brain lesions detected using MRI. They found a non-significant increase risk of silent infarction $(\mathrm{OR}=2.11,95 \% \mathrm{CI} 0.71$ to 6.27$)$ and subcortical brain lesions greater than or equal to $10 \mathrm{~mm}$ $(\mathrm{OR}=1.35,95 \%$ CI 0.56 to 3.22$)$ in those who reported RLS compared with those without RLS. ${ }^{24}$ The small size of this study (26 RLS cases and 241 controls) and limited power to control for confounding by cardiovascular risk factors may explain some of the differences between the results of the MEMO study and our study.

While evidence for a direct association between WML and RLS is limited, some cross-sectional studies have suggested that RLS may be associated with hypertension, ${ }^{14}$ stroke $^{936}$ and migraine, ${ }^{25}{ }^{26}$ which are associated with WML. However, a recent longitudinal study found no association between RLS and incident cardiovascular disease $^{21}$ and not all cross-sectional studies have found associations between hypertension and RLS. ${ }^{911}$ Our study did not find an association between RLS and structural brain lesions which are strongly related to vascular risk factors and cardiovascular disease. This observation aligns with the previous study that did not find an association between RLS and incident cardiovascular disease.

This study has several strengths including the population-based setting with available brain imaging, the size of the cohort, and standardised assessment of RLS using criteria from the International Restless Legs Study Group. ${ }^{1}{ }^{2}$ We also used an automated measurement procedure to quantify and localise WML. Compared with visual scale, automated procedures are not subject to a ceiling effect, permit better discrimination of lesion volume and are more sensitive in detecting small group differences. ${ }^{37}$

Limitations to this study include its cross-sectional design which prevents us from determining the temporal ordering of RLS and WML or examining how RLS may impact WML progression over time. RLS was first assessed in the fifth and sixth waves of the study (approximately 10 years after baseline). Participants who were still in the study then may be healthier than participants who died or dropped out prior to RLS assessment. We did not have information on kidney disease or iron 
Table 2 Cross-sectional age-adjusted and sex-adjusted and multivariable-adjusted* associations between RLS and brain WML volumes

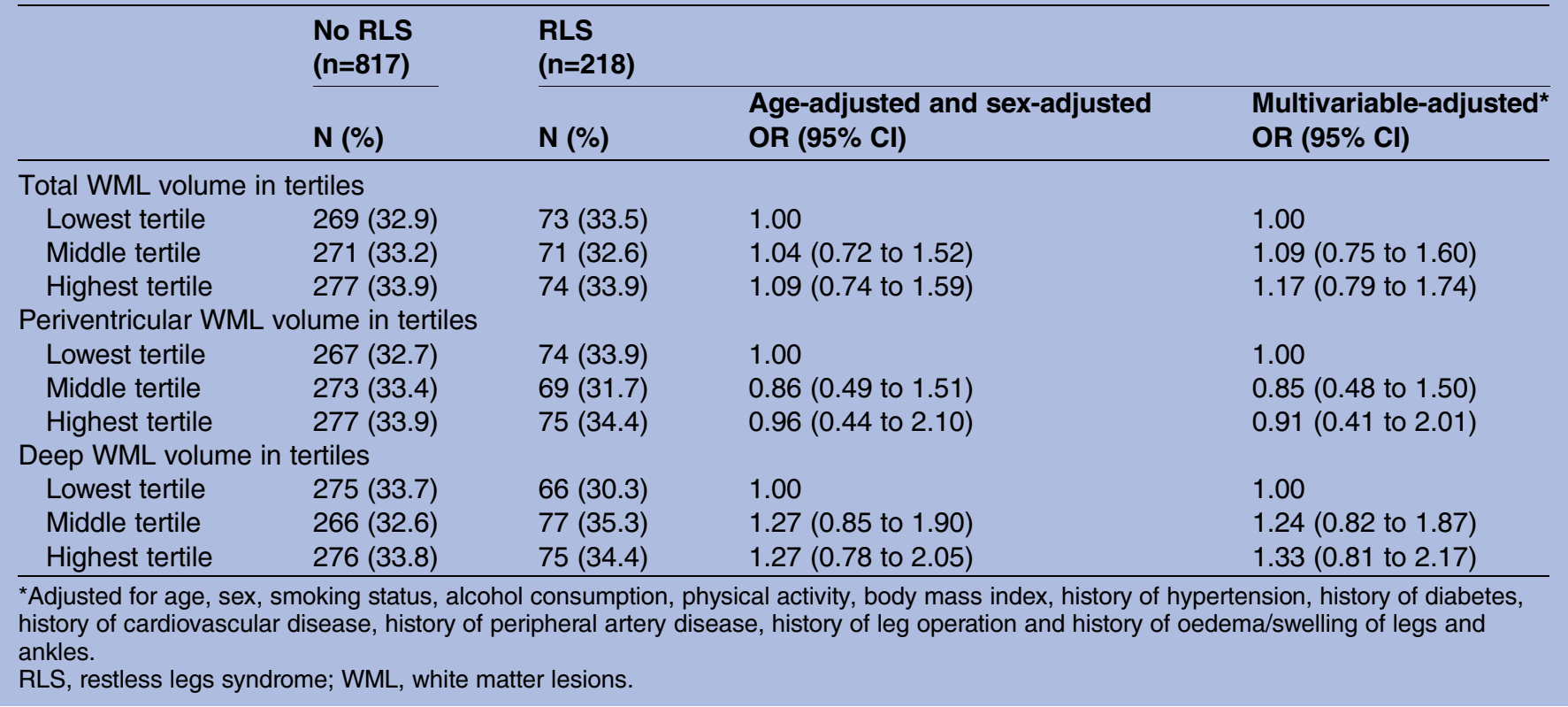

deficiency for participants, which may be related to RLS. Information on RLS was self-reported and potential misclassification is possible. However, we used the best available questionnaire for population-level assessment of RLS and this questionnaire has been validated in previous cohorts. ${ }^{31}{ }^{32}$ Additionally, our questionnaire did not assess RLS severity or periodic limb movements association with RLS so we are unable to determine if the severity of RLS or presence of periodic limb movements may modify the association between RLS and WMH.

While our data do not support a strong association between structural brain lesions and RLS, further targeted research is warranted to evaluate whether subgroups of patients with RLS exist who are at increased risk for structural brain lesions.

\section{Author affiliations \\ ${ }^{1}$ Division of Preventive Medicine, Department of Medicine, Brigham and Women's Hospital, Harvard Medical School, Boston, Massachusetts, USA ${ }^{2}$ Department of Epidemiology, Harvard School of Public Health, Boston, Massachusetts, USA \\ ${ }^{3}$ INSERM Research Center for Epidemiology and Biostatistics (U897) Team Neuroepidemiology, Bordeaux, France \\ ${ }^{4}$ College of Health Sciences, University of Bordeaux, Bordeaux, France ${ }^{5}$ Social and Occupational Determinants of Health, INSERM, Centre for Research in Epidemiology and Population Health, U1018, Villejuif, France ${ }^{6}$ Université de Versailles St-Quentin, Versailles, France \\ ${ }^{7}$ CNRS CEA (UMR5296) Neurofunctional Imaging Group, University of Bordeaux, Bordeaux, France}

Contributors PMR was involved in drafting/revising the manuscript for content, including medical writing for content; study concept or design; and analysis or interpretation of data. CT was involved in obtaining funding, interpretation of data, revising the manuscript for content, and supervision. $A E, A S, C D$ and $B M$ were involved in interpretation of data and revising the manuscript for content. TK was involved in conception and design, interpretation of data, revising the manuscript for content, and supervision. All authors have approved the final version of the manuscript and agree to be accountable for all aspects of the work in ensuring that questions related to the accuracy or integrity of any part of the work are appropriately investigated and resolved.

Funding The 3C study is conducted under a partnership agreement between the Institut National de la Santé et de la Recherche Médicale (INSERM), the Victor Segalen-Bordeaux II University and the Sanofi-Synthélabo Company. The Foundation pour la Recherche Médicale funded the preparation and initiation of the study. The $3 \mathrm{C}$ Study is also supported by the Caisse Nationale Maladie des Travailleurs Salariés, Direction Générale de la Santé, Haute Autorité de la Santé, Institut National de Prévention et d'Education pour la Santé, Conseils Régionaux of Bourgogne, Fondation de France, Ministry of Research-INSERM Program "Cohortes et collections de données biologiques," Mutuelle Générale de l'Education Nationale, Institut de la Longévité, Conseil Général de la Côte d'or. PMR was supported by the Rose Traveling Fellowship Program in Chronic Disease Epidemiology and Biostatistics from the Harvard School of Public Health.

Competing interests PMR has received within the past 2 years funding from a training grant from the National Institute of Aging and from the Rose Traveling Fellowship Program in Chronic Disease Epidemiology and Biostatistics from the Harvard School of Public Health. CT has received fees from the Fondation Plan Alzheimer, the Fondation de Recherche sur l'Hypertension Artérielle, and ABBOTT for participating in scientific committees. He has also received investigator-initiated research funding from the French National Research Agency (ANR) and the Fondation Plan Alzheimer for the $3 \mathrm{C}$ study. TK has received within the past 2 years investigator-initiated research funding from the French National Research Agency, and the US National Institutes of Health. Further, he has received honoraria from the American Academy of Neurology for educational lectures and from the BMJ and Cephalalgia for editorial services. AE has received within the past 2 years investigator-initiated research funding unrelated to this project from the French National Research Agency, EU Joint ProgrammeNeurodegenerative Disease Research (JPND), the French Agency for Drug Security (ANSM), and the French Institute for Research in Public Health (IRESP). CD has received honoraria from the American Academy of Neurology for educational lectures and from Eisai, Inc for providing methodological expertise.

Ethics approval The Ethical Committee of the University Hospital of Kremlin-Bicêtre approved the methods and procedures of the $3 \mathrm{C}$ study.

Provenance and peer review Not commissioned; externally peer reviewed. Data sharing statement No additional data are available. 
Open Access This is an Open Access article distributed in accordance with the Creative Commons Attribution Non Commercial (CC BY-NC 4.0) license, which permits others to distribute, remix, adapt, build upon this work noncommercially, and license their derivative works on different terms, provided the original work is properly cited and the use is non-commercial. See: http:// creativecommons.org/licenses/by-nc/4.0/

\section{REFERENCES}

1. Allen RP, Picchietti D, Hening WA, et al. Restless legs syndrome: diagnostic criteria, special considerations, and epidemiology. A report from the restless legs syndrome diagnosis and epidemiology workshop at the National Institutes of Health. Sleep Med 2003;4:101-9.

2. Walters AS. Toward a better definition of the restless legs syndrome. The International Restless Legs Syndrome Study Group. Mov Disord 1995;10:634-2.

3. Berger K, Kurth T. RLS epidemiology - frequencies, risk factors and methods in population studies. Mov Disord 2007;22(Suppl 18): S420-3.

4. Paulus W, Dowling P, Rijsman R, et al. Pathophysiological concepts of restless legs syndrome. Mov Disord 2007;22:1451-6.

5. Winkelmann J, Schormair B, Lichtner P et al. Genome-wide association study of restless legs syndrome identifies common variants in three genomic regions. Nat Genet 2007;39:1000-6.

6. Ohayon MM, Roth T. Prevalence of restless legs syndrome and periodic limb movement disorder in the general population. J Psychosom Res 2002;53:547-54.

7. Phillips B, Young T, Finn L, et al. Epidemiology of restless legs symptoms in adults. Arch Intern Med 2000;160:2137-41.

8. Sevim S, Dogu O, Camdeviren $\mathrm{H}$, et al. Unexpectedly low prevalence and unusual characteristics of RLS in Mersin, Turkey. Neurology 2003;61:1562-9.

9. Winter AC, Schurks M, Glynn RJ, et al. Vascular risk factors, cardiovascular disease, and restless legs syndrome in women. Am J Med 2013;126:220-7, 27 e1-2.

10. Schlesinger I, Erikh I, Avizohar O, et al. Cardiovascular risk factors in restless legs syndrome. Mov Disord 2009;24:1587-92.

11. Winter AC, Berger K, Glynn RJ, et al. Vascular risk factors, cardiovascular disease, and restless legs syndrome in men. $A m \mathrm{~J}$ Med 2013;126:228-35, 35 e1-2.

12. Kim J, Choi C, Shin K, et al. Prevalence of restless legs syndrome and associated factors in the Korean adult population: the Korean Health and Genome Study. Psychiatry Clin Neurosci 2005;59:350-3.

13. Gao X, Schwarzschild MA, Wang $H$, et al. Obesity and restless legs syndrome in men and women. Neurology 2009;72:1255-61.

14. Batool-Anwar S, Malhotra A, Forman J, et al. Restless legs syndrome and hypertension in middle-aged women. Hypertension 2011;58:791-6.

15. Ulfberg J, Nystrom B, Carter N, et al. Prevalence of restless legs syndrome among men aged 18 to 64 years: an association with somatic disease and neuropsychiatric symptoms. Mov Disord 2001;16:1159-63.

16. Allen $\mathrm{R}$, Chen $\mathrm{C}$, Soaita $\mathrm{A}$, et al. A randomized, double-blind, 6 -week, dose-ranging study of pregabalin in patients with restless legs syndrome. Sleep Med 2010;11:512-19.

17. Juuti AK, Laara E, Rajala U, et al. Prevalence and associated factors of restless legs in a 57-year-old urban population in northern Finland. Acta Neurol Scand 2010;122:63-9.
18. Wesstrom J, Nilsson S, Sundstrom-Poromaa I, et al. Restless legs syndrome among women: prevalence, co-morbidity and possible relationship to menopause. Climacteric 2008;11:422-8.

19. Winkelman JW, Finn L, Young T. Prevalence and correlates of restless legs syndrome symptoms in the Wisconsin Sleep Cohort. Sleep Med 2006;7:545-2.

20. Winkelman JW, Shahar E, Sharief I, et al. Association of restless legs syndrome and cardiovascular disease in the Sleep Heart Health Study. Neurology 2008;70:35-42.

21. Winter AC, Schurks M, Glynn RJ, et al. Restless legs syndrome and risk of incident cardiovascular disease in women and men: prospective cohort study. BMJ Open 2012;2:e000866.

22. Li Y, Walters AS, Chiuve SE, et al. Prospective study of restless legs syndrome and coronary heart disease among women. Circulation 2012;126:1689-94.

23. Li Y, Wang W, Winkelman JW, et al. Prospective study of restless legs syndrome and mortality among men. Neurology 2013:81:52-9.

24. Walters AS, Moussouttas M, Siddiqui F, et al. Prevalence of stroke in Restless Legs Syndrome: Initial Results Point to the Need for More Sophisticated Studies. Open Neurol J 2010;4:73-7.

25. Schurks M, Winter AC, Berger K, et al. Migraine and restless legs syndrome in women. Cephalalgia 32:382-9.

26. Winter AC, Schurks M, Berger K, et al. Migraine and restless legs syndrome in men. Cephalalgia 33:130-5.

27. Group CS. Vascular factors and risk of dementia: design of the Three-City Study and baseline characteristics of the study population. Neuroepidemiology 2003;22:316-25.

28. Maillard $\mathrm{P}$, Delcroix N, Crivello F, et al. An automated procedure for the assessment of white matter hyperintensities by multispectral (T1, T2, PD) MRI and an evaluation of its between-centre reproducibility based on two large community databases. Neuroradiology 2008;50:31-42.

29. Soumare A, Elbaz A, Zhu Y, et al. White matter lesions volume and motor performances in the elderly. Ann Neurol 2009;65:706-15.

30. Zhu YC, Dufouil C, Soumare A, et al. High degree of dilated Virchow-Robin spaces on MRI is associated with increased risk of dementia. J Alzheimers Dis 2010;22:663-72.

31. Berger K, von Eckardstein A, Trenkwalder C, et al. Iron metabolism and the risk of restless legs syndrome in an elderly general population-the MEMO-Study. J Neurol 2002;249:1195-9.

32. Hogl B, Kiechl S, Willeit J, et al. Restless legs syndrome: a community-based study of prevalence, severity, and risk factors. Neurology 2005;64:1920-4.

33. The Expert Committee on the Diagnosis and Classification of Diabetes Mellitus. Report of the Expert Committee on the Diagnosis and Classification of Diabetes Mellitus. Diabetes Care 1997;20(7): 1183-97.

34. Boulos M, Pettersen J, Jewell D, et al. Nocturnal limb movements are correlated with cerebral white matter hyperintensities. Neurology 2012;78:P05.001.

35. Henskens LH, Kroon AA, van Oostenbrugge RJ, et al. Associations of ambulatory blood pressure levels with white matter hyperintensity volumes in hypertensive patients. J Hypertens 2009;27:1446-52.

36. Elwood P, Hack M, Pickering J, et al. Sleep disturbance, stroke, and heart disease events: evidence from the Caerphilly cohort. $J$ Epidemiol Community Health 2006;60:69-73.

37. van Straaten EC, Fazekas F, Rostrup E, et al. Impact of white matter hyperintensities scoring method on correlations with clinical data: the LADIS study. Stroke 2006;37:836-40. 